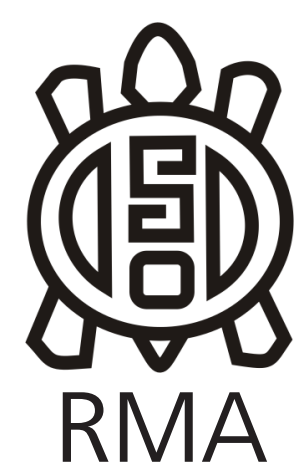

Dossier

\title{
Caracterización de fuentes líticas, estudios de selección y aprovisionamiento y sus implicancias en las prácticas sociales
}

\author{
From the sources: New approaches for the study of the selection and \\ procurement of rocks and their implications for social practices
}

Manuel E. Cueto*, Ariel D. Frank* y Fabiana Skarbun*

* CONICET, División Arqueología, Facultad de Ciencias Naturales y Museo, Universidad Nacional de La Plata, Argentina. E-mail: manuelcueto@fcnym.unlp.edu.ar, frank.ariel@gmail.com, fskarbun@fcnym.unlp.edu.ar

Este dossier reúne trabajos presentados en el simposio "Desde las fuentes: avances en los estudios de selección y aprovisionamiento de rocas y sus implicancias en las prácticas sociales" realizado en el marco del $1^{\circ}$ Congreso Argentino de Estudios Líticos en Arqueología. Las exposiciones fueron realizadas en un fructífero marco de discusión de propuestas teóricas, planteos metodológicos, y casos de estudio, que dieron como resultado los siete trabajos aquí publicados. Los estudios permiten establecer una serie de ejes temáticos que exponen intereses de investigación orientados a la caracterización arqueológica y geológica de fuentes de materias primas, a evaluar los avances generados desde diversas aproximaciones metodológicas, y otros destinados a indagar acerca de las estrategias de producción, intercambio e interacción implementadas por los pueblos en el pasado.

Estas investigaciones expresan que el estudio de la gestión de los recursos líticos por parte de diversas sociedades ha ido cambiando en los últimos años con el surgimiento de enfoques en los que la materialidad ha sido considerada desde una óptica integradora. Como resultado de la implementación de perspectivas dinámicas de la tecnología, la composición y estructuración final de los conjuntos artefactuales ha sido atribuida a la articulación de una serie de elecciones y procesos de trabajo que van desde la obtención de la materia prima hasta el uso de los artefactos.

El primer eje temático involucra la estructuración y aplicación de abordajes metodológicos que combinan múltiples perspectivas para el estudio de fuentes en diversas regiones del país. En este sentido el trabajo de Heider y colaboradores caracteriza arqueológica y geológicamente canteras y fuentes de rocas silíceas de las Sierras Pampeanas Orientales a escala macrorregional. Evalúa los procesos geológicos y geomorfológicos que intervinieron en la génesis y transformación de estas materias primas. Propone un modelo de yacencia para las rocas, compuesto por dos grupos principales: a) cuarzo y calcedonia en rocas del basamento ígneo-metamórfico y b) calcedonia y ópalo en sedimentos cenozoicos, que sugieren distinto origen y antigüedad. En consecuencia, los autores esperan que la caracterización química y petrográfica de los materiales permita a futuro contribuir a la compleja problemática de reconocer la proveniencia de los artefactos hallados en contextos arqueológicos. Skarbun y colaboradores analizan la estructura de recursos y las formas de explotar las fuentes líticas de la localidad La María en Santa Cruz, la cual presenta un paisaje con alta disponibilidad de rocas. Los autores ponen énfasis en la metodología, implementando estrategias que combinan la caracterización geológica y la localización de fuentes en campo, con buen soporte cartográfico y de sistemas de información geográfica. Estudian numerosas fuentes de excelente calidad, mediante relevamientos y estudios contextuales con diversos grados de resolución. Además, su aproximación articula la clasificación tecnomorfológica in situ de artefactos, la determinación petrográfica, y estudios experimentales. Proponen que los grupos utilizaron las fuentes para el aprovisionamiento de rocas implementando estrategias tecnológicas similares, durante amplios lapsos temporales. Sugieren que existe una estructuración intersitio en las actividades de manufactura, con intensa actividad inicial de talla en las canteras. Estas prácticas no implicaron estrategias para optimizar el rendimiento de las rocas, que luego eran trasladadas a los sitios de actividades múltiples, para finalizar allí la confección de artefactos.

Otro eje sobre el que se articularon trabajos es el estudio de las estrategias de explotación de la obsidiana, abordando la movilidad e interacción por parte de sociedades del noroeste argentino durante distintos momentos del Holoceno. Estos trabajos demuestran la riqueza y amplitud de temas que es posible abordar si se conoce la procedencia de las materias primas. De esta manera, el trabajo de Martínez y Funes Coronel analiza los vínculos establecidos entre comunidades asentadas en dos áreas distantes, los valles intermontanos tucumanos y la puna catamarqueña, durante el Holoceno temprano y medio. Desarrollan sus reflexiones considerando que en ambas regiones se reconocieron materiales de origen no local que remiten a procesos de interacción. Identifican 
en la puna madera y caña procedente de los valles y yungas, empleados para la confección de astiles, mientras que en los valles intermontanos reconocen obsidiana proveniente del sector puneño. A su vez determinan que las comunidades de ambas regiones comparten diseños de puntas de proyectil. Interpretan que las comunidades de los valles habrían sido autosuficientes y no habrían dependido de recursos foráneos mientras que los grupos puneños necesitaron de los recursos vegetales para confeccionar armas. En consecuencia los diseños de puntas habrían surgido en los valles y luego habrían sido replicados en la puna. Por otra parte, en una escala geográfica más amplia, Mercuri evalúa los rangos de acción de poblaciones prehispánicas considerando la distribución de obsidianas alóctonas identificadas en contextos arqueológicos de Tucumán, Salta y Jujuy. Estos poseen cronologías en torno a los 2000 años AP, momento de importantes cambios sociales en los Andes Meridionales. Para su estudio tiene en cuenta la procedencia de estas materias primas desde fuentes distantes, tanto como las distintas etapas de las cadenas operativas presentes en los sitios y las funcionalidades propuestas para estos espacios. De esta manera, se basa en ideas previas para afirmar que los patrones que presentan los conjuntos líticos no pueden explicarse solamente por las pautas de movilidad y aspectos funcionales, sino que deben considerarse también la organización social, las redes de interacción y la circulación de materias primas. Por su parte, Varde documenta los patrones de uso de obsidianas en la ocupación tardía de Cueva Nacimiento 1, en la puna salteña. A partir de análisis arqueométricos y tecnomorfológicos infiere que todas las variedades de obsidiana presentes provienen de fuentes no locales. Indaga sobre el rol que cumplieron estas rocas en las estrategias tecnológicas implementadas, estimando la inversión de energía en la manufactura de instrumentos y evaluando diferencias y similitudes en el aprovechamiento de las obsidianas y las rocas locales de buena calidad. Identifica que la obsidiana predomina y forma parte de casi toda la gama de instrumentos elaborados, tanto para la confección de artefactos de baja inversión de trabajo como para las puntas de proyectil -de mayor inversión de energía y estrategias tecnológicas conservadas- De esta manera, la autora concluye que la obsidiana estuvo disponible y fue seleccionada como consecuencia de la implementación de redes de interacción e intercambio que facilitaron el acceso a las mismas, probablemente en paralelo a otros bienes de valor económico o simbólico. Esto habría contribuido a formar y legitimar relaciones sociales, y reforzar la reproducción social.

Encontramos otro eje temático en trabajos orientados al estudio de las decisiones y prácticas tecnológicas vinculadas con la explotación de rocas, llevadas a cabo por sociedades con importantes diferencias en su modo de vida. Estas investigaciones exponen por un lado los aspectos económicos que inciden en las prácticas de aprovisionamiento, pero al mismo tiempo dan cuenta de cómo la producción lítica está integrada a un repertorio más amplio de actividades en los cuales intervienen diferentes sectores de una comunidad o requieren de la interacción con otros grupos. Por un lado, Banegas y Gómez Otero evalúan el aprovechamiento del xilópalo en dos sectores del litoral marítimo de Chubut. Exploran la relación entre la frecuencia de artefactos de esta litología en contextos datados, y la distribución, calidad y composición química de las fuentes locales. Así, proponen que en ambos sectores la calidad de los nódulos de xilópalo utilizados es muy buena a excelente; mientras los artefactos tendrían tamaños mayores en la costa sur, espacio donde se habría aprovechado más esta roca. Sugieren que hubo una vinculación estrecha entre la intensidad de uso de los xilópalos y la oferta local: en el sector sur, debido a la menor distancia respecto de los afloramientos primarios, hubo un mayor aprovechamiento y obtención directa de la materia prima. En el sector norte su adquisición se habría dado mediante mecanismos indirectos -a través del intercambio- y hallazgos fortuitos en los afloramientos. Por su parte Coloca discute las evidencias incaicas vinculadas con la explotación lapidaria de turquesa proveniente de dos sitios ubicados en la puna de Salta. Postula a Cerro Inca Viejo como la primera fuente con extracción prehispánica de dicho mineral para el NOA. El autor indica que la explotación de turquesa fue muy importante durante la ocupación incaica. Para efectuar una minería eficiente a gran escala el Tawantinsuyu desarrolló en el área un sistema organizativo que tuvo fuertes implicancias sociales. Esta requirió la instalación del poblado Abra de Minas, áreas de trabajo cercanas a los pozos extractivos y la construcción de arquitectura ceremonial. En este sentido, Coloca interpreta que el registro vinculado con prácticas rituales estaría relacionado con la propiciación de festividades por parte del Imperio en las que destacaba la hospitalidad y el agasajo, como parte de una estrategia asociada con una dominación simbólica sobre las poblaciones locales, y posiblemente sobre los grupos trasladados para trabajar en las minas.

Creemos que este dossier constituye una buena representación de las diversas ópticas y vías de análisis con las que se abordan las prácticas sociales a partir de distintas materialidades asociadas a las fuentes de aprovisionamiento, en diversos paisajes habitados por comunidades originarias. Además, agradecemos a los autores, a los evaluadores que con sus comentarios mejoraron estas contribuciones, a los organizadores del CAELA y a los editores generales de la Revista del Museo de Antropología. 